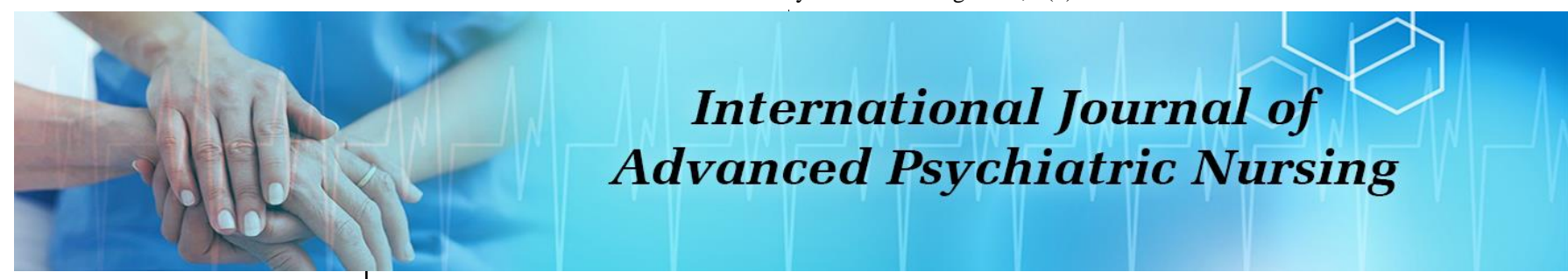

E-ISSN: 2664-1356 P-ISSN: 2664-1348 www.psychiatricjournal.net IJAPN 2022; 4(1): 07-11 Received: 07-11-2021 Accepted: 09-12-2021

Dr. Smriti G Solomon Principal, Index Nursing College, Village -Morodhat, Indore, Madhya Pradesh, India

\section{Effect of anuloma and viloma pranayama on stress of nurses}

\author{
Dr. Smriti G Solomon
}

DOI: https://doi.org/10.33545/26641348.2022.v4.i1a.74

\begin{abstract}
Background: Nurses are an integral component of the health care delivery system. Nurses encounter a variety of stressors while discharging their duties. Mind-body interventions are beneficial in stressrelated mental and physical disorders. Yogic breathing is a unique method for influencing psychological and stress-related disorders.

Aim: To evaluate the effect of Anuloma and Viloma Pranayama on stress among nurses.

Method and Materials: A pre experimental one group pretest posttest design was adopted for study. 296 female nurses were selected using nonprobability purposive sampling technique. Modified Expanded Nursing Stress Scale (ENSS) was used to measure the stress of clinical nurses. The pre test stress level was evaluated on the day 1 and then the CD of video-assisted intervention on anuloma and viloma pranayama was distributed among participants and were instructed to perform anuloma and viloma pranayama for six months and post test stress level was evaluated on day 180.

Result: Result revealed that major nursing stress factors causing stress to the participants were economical and professional growth stressors, direct patient care, patient and family stressors and workload stressors, caused significantly higher stress among participants. Overall mean pre-test stress value was $106.12 \pm 26.34$, while the mean post-test stress value was $70.48 \pm 15.18$. After the intervention, a statistically significant decrease in the stress level was seen in nurses and the difference was found to be statistically significant $(P<0.05)$.

Conclusion: The video-assisted intervention of anuloma and viloma pranayama used in this study was effective in reducing stress of clinical nurses.
\end{abstract}

Keywords: Nurses, stress, stressors, yoga, anuloma - viloma pranayama

\section{Introduction}

Nurses are an integral component of the health care delivery system. Nurses encounter a variety of stressors while discharging their duties. The term "stress", was coined by Hans Selye in 1936, who defined it as "the non-specific response of the body to any demand for change" [1]. "Psychological stress is a particular relationship between the person and the environment that is appraised by the person as taxing or exceeding his or her resources and endangering his or her well-being" [2]. Stress results from a change in the environment that is perceived as a challenge, a threat or a danger and to have both positive and negative effects. The primary sources of occupational stress among nursing staff identified were very high degree of responsibility and accountability ${ }^{[3]}$.

Pranayama is derived from two words - prana, which means life force and ayama, which means to expand. Therefore, the word Pranayama means the expansion of life force ${ }^{[4]}$. Anulom Vilom Pranayama is a popular breathing exercise associated with traditional yoga which is used to calm the mind and body ${ }^{[5]}$.

\section{Need of the study}

According to the US Bureau of Labor Statistics (2021), Registered nurses held about 3.1 million jobs in 2020 and of those, $61 \%$ of nurses are employed at state, local and private hospitals. They are responsible for patient care, educating patients about their health conditions and act as a sympathetic caregiver. Nurses who work in hospitals and nursing care facilities usually work in shifts to provide round-the-clock coverage ${ }^{[6]}$.

World Health Organization (2018), Global Health Observatory data, reported that over 55\% of WHO Member States report to have less than 40 nursing and midwifery personnel per 10 000 population (about $23 \%$ report to have less than 10 ). In many countries nurses and 
midwives constitute more than $50 \%$ of the national health workforce ${ }^{[7]}$. The main sources of distress for nurses for many years were workload, leadership/management style, professional conflict and emotional cost of caring, lack of reward and shift working ${ }^{[8]}$, shortage of staff, and role conflicts [9], heavy workload, repetitive work, and poor working environment were major contributor of job stress among nurses ${ }^{[10]}$.

Most stressful subscale for nurses was dealing with patients and their families as "Frequently Stressful" [11]. Death and dying of patients as "Extremely Stressful" [12]. High workloads, unavailability of doctors, unsupportive management, human resource issues, interpersonal issues, patients' relatives, shift work, car parking, handover procedures, and no common area for nurses were the sources of occupational stress ${ }^{[13]}$. Nurses reported that no time for rest, of whom $42 \%$ were suffering from moderateto-severe stress ${ }^{[14]}$, a low satisfaction level with contingent reward, fringe benefits, and pay ${ }^{[15]}$. Register nurses working overtime reported an $88 \%$ increase in failing or poor patient safety, a $45 \%$ increase in fair or poor quality of nursing care, and an $86 \%$ increase in care left undone ${ }^{[16]}$.

Hence, the researcher found that it is important to understand the impact of video assisted intervention of yoga on the stress of clinical nurses because of the physiological and mental harm caused by stress adversely affect the delivery of patient care by these nurses. The practice of pranayama through video will be helpful to educate nurses about stress relief. This strategy needs to be empirically evaluated for their efficacy in reducing the stress of clinical nurses so there was the need to conduct this study.

\section{Problem Statement}

A study to evaluate the effect of video-assisted intervention on anuloma viloma pranayama on stress reduction among clinical nurses working in selected hospitals of Madhya Pradesh.

\section{Objectives of the study}

- To assess pre interventional level of stress among clinical nurses working in selected hospitals of Madhya Pradesh.

- To compare pretest and posttest level of stress among clinical nurses working in selected hospitals of Madhya Pradesh.

- To find out the association of pretest stress score with selected demographic variables of clinical nurses working in selected hospitals of Madhya Pradesh.

\section{Hypothesis}

- H1: There will be a significant reduction in stress level after video-assisted intervention on anuloma and viloma pranayama among clinical nurses at 0.05 level of significance.

- H2: There will be a significant association of preinterventional levels of stress among clinical nurses with their selected demographic variables at 0.05 level of significance.

\section{Conceptual Framework}

The conceptual framework of this study is based on Modified Betty Neuman's systems model (1972), which is concerned with variances from wellness, the presence of stressors, and the need of the client system to attain and maintain stability ${ }^{[17]}$.

\section{Materials and Methods}

The present study was aimed to evaluate the effect of Anuloma and Viloma Pranayama in reduction of stress among clinical nurses. Quantitative approach was used. A pre experimental one group pretest posttest design was adopted for study. The setting of the study was selected hospitals of Madhya Pradesh. Samples were registered clinical nurses who fulfill the designated set of criteria of interest to the researcher and was selected using non probability purposive sampling technique. The sample size comprised of 296 clinical nurses working in Medical Unit, Surgical Unit, Paediatric Unit, Obstetrics and Gynaecology Unit. The pre test stress level of clinical nurses was evaluated on the day 1 by administering Modified Expanded Nursing Stress Scale (ENSS) and then the CD of videoassisted intervention on anuloma and viloma was distributed among participants and was instructed to perform anuloma and viloma pranayama for six months and post test stress level was evaluated on day 180.

\section{Result and Discussion \\ Section I: Distribution of participants according to demographic characteristics}

Maximum 155 (52.4\%) participants were in the age group 23-27 years, 187(63.2\%) participants belonged to nuclear family, $214(72.3 \%)$ participants' parents formed the social support group, 123 (41.6\%) participants had done their GNM, 13 (4.4\%) had done their Post basic B.Sc. Nursing, $154(52.0 \%)$ had done their B.Sc. Nursing and only 6 (2.0\%) had done their M.Sc. Nursing. There were four working units selected - Medical Unit, Surgical Unit, Obstetric and Gynecologic Unit and Pediatric Unit, each unit had equal distribution of participants i.e. 74 (25.0\%), Majority of the nurses 295 (99.7\%) were doing duty by rotation, $193(65.2 \%)$ participants were having $1-5$ years of experience.

\section{Section II: Comparison of pretest posttest level of stress among clinical nurses}

Table 1: Comparison of pretest and posttest stress level ( $\mathrm{N}=296)$

\begin{tabular}{|c|c|c|c|c|c|}
\hline S. No. & Stress Grading & \multicolumn{2}{|c|}{ Pretest } & \multicolumn{2}{|c|}{ t } \\
\hline & & No. & $\mathbf{\%}$ & No. & \% \\
\hline 1. & No stress & 0 & 0.0 & 0 & 0.0 \\
\hline 2. & Mild Stress & 23 & 7.8 & 123 & 41.6 \\
\hline 3. & Moderate Stress & 227 & 76.7 & 173 & 58.4 \\
\hline 4. & Severe Stress & 46 & 15.5 & 0 & 0.0 \\
\hline & Total & 296 & 100.0 & 296 & 100.0 \\
\hline
\end{tabular}




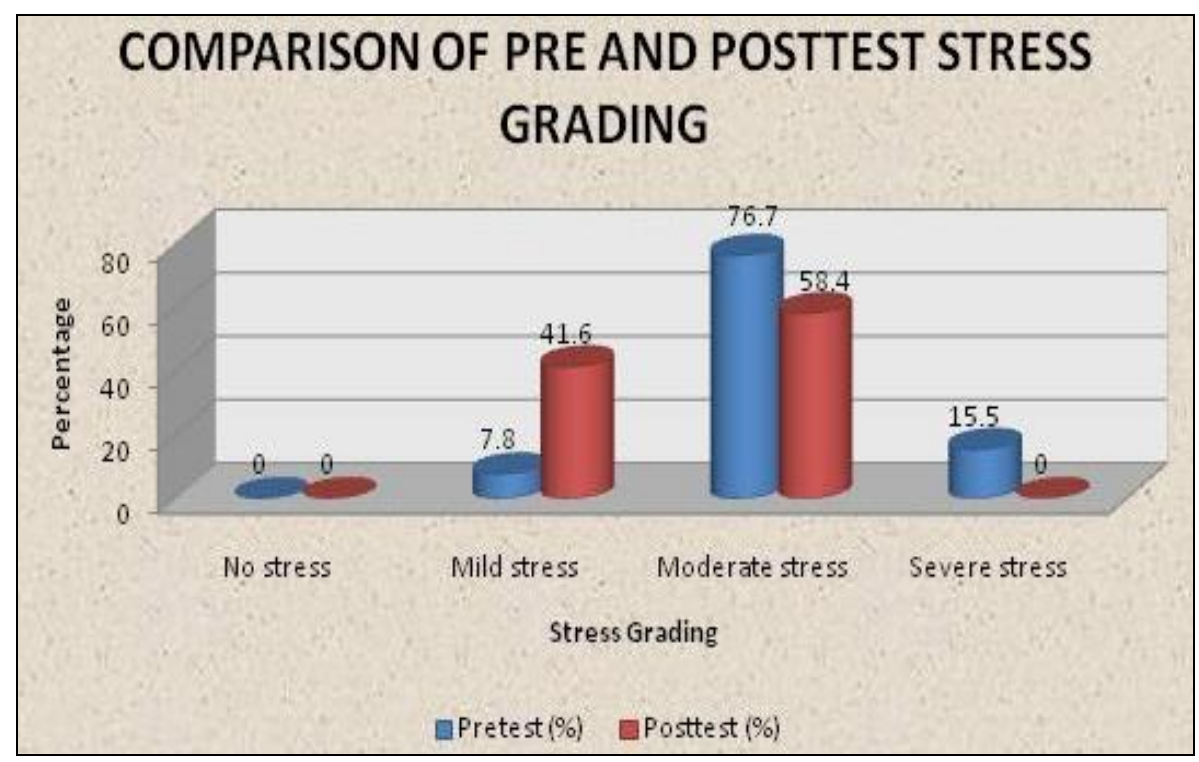

Fig 1: Bar diagram showing comparison of pre and posttest stress grading

Table No.1 and fig.1 show that before intervention, 23 (7.8\%) participants had mild stress, 227 (76.7\%) participants had moderate stress and $46(15.5 \%)$ had severe stress. After the intervention, $123(41.6 \%)$ participants had mild stress, $173(58.4 \%)$ participants had moderate stress and none had severe stress. There was reduction in the stress after the intervention

Table 2: Comparison of mean pretest and posttest level of stress among clinical nurses

\begin{tabular}{|c|c|c|c|c|}
\hline Nursing Stress Factor & Pretest Mean \pm SD & Posttest Mean \pm SD & 't' Value & P Value \\
\hline Factor 1: Direct patient care Stressors & $11.43 \pm 3.37$ & $7.78 \pm 2.39$ & 31.712 & $0.000^{*}$ \\
\hline Factor 2: Health professional Conflict Stressors & $10.81 \pm 3.66$ & $7.17 \pm 1.96$ & 24.833 & $0.000^{*}$ \\
\hline Factor 3: Inadequate Emotional Preparation Stressors & $10.15 \pm 3.13$ & $6.86 \pm 1.89$ & 27.988 & $0.000^{*}$ \\
\hline Factor 4: Problems with Peers Stressors & $9.88 \pm 3.67$ & $6.82 \pm 2.20$ & 22.691 & $0.000^{*}$ \\
\hline Factor 5: Problems with Supervision Stressors & $10.57 \pm 4.12$ & $6.74 \pm 2.18$ & 23.459 & $0.000^{*}$ \\
\hline Factor 6: Workload Stressors & $11.23 \pm 3.59$ & $7.61 \pm 2.29$ & 26.598 & $0.000^{*}$ \\
\hline Factor 7: Uncertainty Concerning Treatment Stressors & $10.64 \pm 3.84$ & $6.95 \pm 2.16$ & 25.001 & $0.000^{*}$ \\
\hline Factor 8: Patient and Family Stressors & $11.41 \pm 3.66$ & $7.32 \pm 2.19$ & 27.828 & $0.000^{*}$ \\
\hline Factor 9: Discrimination Stressors & $6.85 \pm 3.69$ & $4.63 \pm 2.22$ & 16.753 & $0.000^{*}$ \\
\hline Factor 10: Economical and professional growth stressors & $13.14 \pm 4.48$ & $8.58 \pm 2.75$ & 28.136 & $0.000^{*}$ \\
\hline Overall & $106.12 \pm 26.34$ & $70.48 \pm 15.18$ & 35.119 & $0.000^{*}$ \\
\hline
\end{tabular}

Paired ' $\mathrm{t}$ ' test applied. $\mathrm{P}$ value $<0.05$ was taken as statistically significant

Table 2 shows that overall the mean pretest stress value was $106.12 \pm 26.34$, while the posttest stress value was $70.48 \pm$
15.18. The difference was found to be statistically significant $(P<0.05)$, showing a lower posttest stress value.

\section{COMPARISON OF MEAN STRESS LEVEL ACCORDING TO EACH FACTOR}

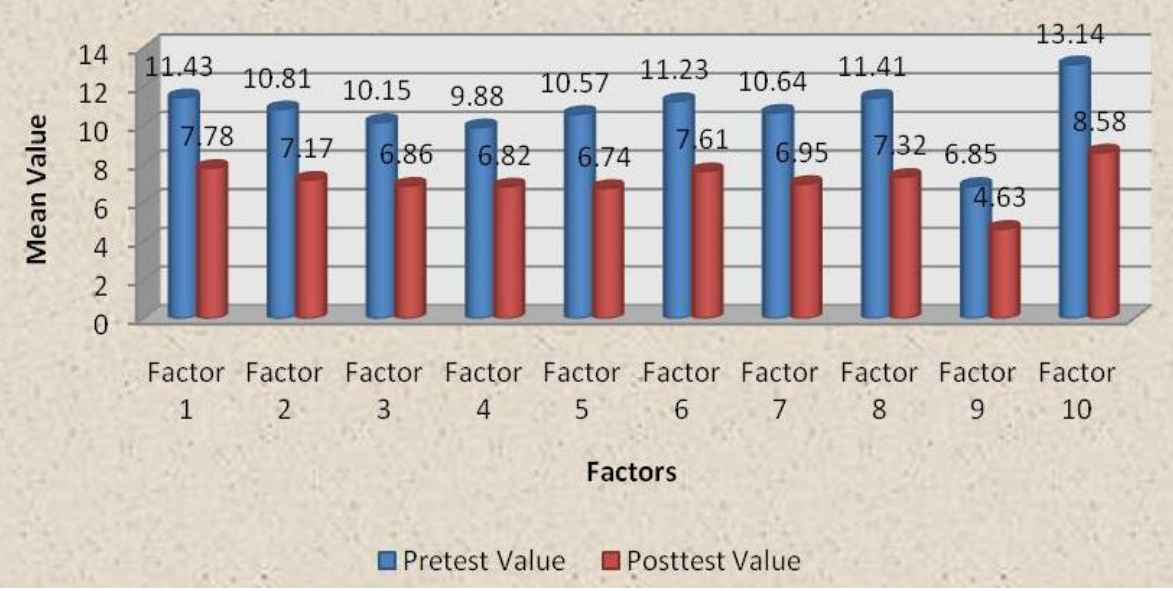

Fig 2: Bar diagram showing comparison of mean stress level according to each factor 
After the intervention, there was a statistically significant decrease in the stress from pretest to posttest among clinical nurses at 0.05 level of significance, hence the hypothesis H1which states, "There will be a significant reduction in stress level after video-assisted intervention on Anuloma and Viloma Pranayama among clinical nurses at 0.05 level of significance", is accepted.

Section III: To find association of pre interventional level of stress with selected demographic variables of clinical nurses.

The association of age and years of experience were found to be statistically significant $(P<0.05)$ with the pre-stress grade, showing that the stress level is dependent on the age and years of experience of the participants, as the age and years of experience increases the stress level decreases.

\section{Discussion}

Maximum 155 (52.4\%) participants were in the age group 23-27 years, $187(63.2 \%)$ participants belonged to nuclear family, $214(72.3 \%)$ participants' parents formed the social support group, and 123 (41.6\%) participants had done their GNM. Data was collected from the participants working in Medical Unit, Surgical Unit, Obstetric and Gynecologic Unit and Pediatric Unit, each unit had equal distribution of participants i.e. 74 (25.0\%), Majority of the nurses 295 $(99.7 \%)$ were doing duty by rotation, 193 (65.2\%) participants were having 1-5 years of experience.

Before the intervention, 23 (7.8\%) participants had mild stress, 227 (76.7\%) participants had moderate stress and 46 $(15.5 \%)$ had severe stress. After the intervention, there were 123 (41.6\%) participants with mild stress, 173 (58.4\%) participants with moderate stress and none were having severe stress. There was a decrease in the stress level after the intervention.

Major nursing stress factors causing stress to the participants were evaluated and result revealed that economical and professional growth stressors the mean pretest stress value was $13.14 \pm 8.58$, while the posttest stress value was $8.58 \pm 2.75$, direct patient care stressor the mean pretest stress value was $11.43 \pm 3.37$, while the posttest stress value was $7.78 \pm 2.39$, patient and family stressors the mean pretest stress value was $11.41 \pm 3.66$, while the posttest stress value was $7.32 \pm 2.19$ and workload stressors the mean pretest stress value was $11.23 \pm 3.59$, while the posttest stress value was $7.61 \pm 2.29$, caused significantly higher stress among participants. Overall mean pretest stress value was $106.12 \pm 26.34$, while the posttest stress value was $70.48 \pm 15.18$. The difference was found to be statistically significant $(P<0.05)$, showing a lower posttest stress value. After the intervention, there was a statistically significant decrease in the stress value in each of the factors and also the overall stress.

After the intervention, there was a statistically significant decrease in the stress from pretest to posttest among clinical nurses at 0.05 level of significance, hence the hypothesis H1which states, "There will be a significant reduction in stress level after video-assisted intervention on anuloma and viloma pranayama among clinical nurses at 0.05 level of significance" is accepted.

Pearson Chi square test applied to find out the association of various demographic variables with pre-stress level. On analysis of data age and years of experience were found to be statistically significant $(P<0.05)$ showing that as the age and years of experience increases the stress level decreases. While all the other demographic variables were not found to be statistically significant $(P<0.05)$ with the pre-stress level.

\section{Conclusion}

Clinical nurses experienced economical and professional growth stressors, direct patient care stressors, patient and family stressors and workload stressors as the major stressors and video assisted intervention on yoga was effective in reducing stress among clinical nurses as a coping strategy. Nurse administrator should encourage nurses to participate in yoga programme and practice yoga daily for avoiding stress and keeping the stress level at the minimum towards mentally, physically and socially healthy. Unstressful personality, also helpful to be as peaceful health care provider, which in turn will help nursing administrators to have smooth functioning by saving time, energy, money and material.

\section{References}

1. Tan Siang Yong et al. Hans Selye (1907-1982): Founder of the stress theory. Singapore Med J. 2018;59(4):170-171.

2. Lazarus and Folkman, 1984, 19p.

3. Sarafis $\mathrm{P}$ et al. the impact of occupational stress on nurses' caring behaviors and their health related quality of life. BMC Nurs. 2016;15:56.

4. Jiva Ayurveda. Benefits and Techniques of AnulomVilom Pranayama, 2019.

5. Urban Company Desk. Health Benefits of Anulom Vilom Pranayama, 2020.

6. Occupational outlook handbook. US Bureau of Labor Statistics. Retrieved from

https://www.bls.gov/ooh/healthcare/registerednurses.htm\#tab-3

7. World Health Organization. Global Health Observatory data, 2018. Retrieved from

https://www.who.int/data/gho/data/indicators/indicatordetails/GHO/nursing-anddensity-(per-1000-population)

8. McVicar A. Workplace stress in nursing: a literature review. Adv Nur. 2003 Dec;44(6):633-42.

9. Lim J. Stress and coping in Singaporean nurses: a literature review. Nursing Health Science. 2010;12(2):251-280.

10. Beh Loo-See. Job Stress and Coping Mechanisms among Nursing Staff in Public Health Services. International Journal of Academic Research in Business and Social Sciences. 2012 July, 2(7).

11. Samar M. The effect of nurses' Perceived Job Related Stressors on Job Satisfaction in Taif Governmental Hospitals in Kingdom of Saudi Arabia. Journal of American Science. 2012;8(3):119-125.

12. Saleh Ahmad M et al. The impact of stress on job satisfaction for nurses in King Fahad pecialist HospitalDammam-KSA, Journal of American Science. 2013;9(3):371-377.

13. Brenda Happell et al. Nurses and stress: recognizing causes and seeking solutions. Journal of Nursing Management. 2013 May;21(4):638-647.

14. Sharma Parul et al. Occupational stress among staff nurses: Controlling the risk to health. Indian J Occup Environ Med. 2014 May-Aug;18(2):52-56. 
15. Masum A. Job satisfaction and intention to quit: an empirical analysis of nurses in Turkey. Peer Journal, 2016. Retrieved from

https://pubmed.ncbi.nlm.nih.gov/27168960/

16. Cho E. Nurse staffing level and overtime associated with patient safety, quality of care, and care left undone in hospitals: A cross-sectional study. International Journal Nursing Studies. 2016;60:263-71.

17. Neuman B. Betty Neuman's System Model. 2012. Retrieved from

https://www.scribd.com/document/62509271/BettyNeuman. 